\title{
A Knowledge Testing Production Model Based on a Cognitive Map for SWI-Prolog Applications
}

\author{
http://dx.doi.org/10.3991/ijet.v10i6.4868 \\ Dmitry I. Popov, Olga Y. Lazareva \\ Moscow State University of Printing Arts, Moscow, Russia
}

\begin{abstract}
In this paper, we describe the ways of improving knowledge assessment with the help of cognitive maps made during the process of working with an intelligent tutoring system, E-learning center - High-edu. Cognitive maps consist of didactic units - minimal units of knowledge about some discipline's domain. This article shows how they can be used in intelligent tutoring systems. An example of algorithm realization for forming a didactic units list from a discipline cognitive map for consistency of test task presentation determining is shown. An operator model is presented in this paper, which can be helpful for researchers and engineers using Prolog language for expert systems and knowledge management system development as well as for support of the educational process and control of student knowledge to improve the quality of electronic education.
\end{abstract}

Index Terms-intelligent tutoring system, cognitive map, knowledge management, production model, SWI-Prolog.

\section{INTRODUCTION}

Assessment tests are one of the most powerful, reliable and objective methods of defining students' learning success [1]. Inasmuch as test units provide a clear and correct indication of a testee on the required testing assertion, it is possible to realize an automated check of the testees' answer correctness on test units. These include both usual testing systems that provide a random list of questions chosen from a test material bank (TMB) and adaptive systems, which are questions chosen by algorithms that consider previous test tasks and answers on them [2-6].

The intelligent tutoring system, E-learning Center High-Edu (ELC-HE) [7, 8], developed by the authors, allows building cognitive maps of courses by an expert group or an expert (e.g. a tutor). Cognitive maps with a production model can be used to improve the testing score.

Cognitive maps are an academic subject object domain [9-11] model in the form of a semantic web with considered relations "Previous - next" between didactic units (DU) studied in the context of a certain discipline [12]. DU is realized as the "logic independent education material corresponding by volume and structure to content elements such as idea, theory and law" [13]. Weights of relations between the DU describe the importance of the knowledge of one DU for learning another.

In the ELC-HE system, every test task from the TMB is turned to check student knowledge on the specific DU, and because of that the following problems can be solved:

1. Choose the sequence of test task presentation.
2. Take into account the probably guessed correct answers and the randomly guessed answers by students in the final score.

\section{Test TAsk Presentation Order}

In the majority of testing systems, the choice of the next shown test task takes place either randomly or based on an adaptive algorithm [5], choosing tasks by complexity level. However neither the first nor the second type of testing system considers the sequence of learning ideas, laws, theorems and other DU in the course.

The student answering at the beginning of testing about the DU learned at the end of the course may not remember the needed material. Through an oral test, the tutor might ask a leading question and help the student give the correct answer. For example, by testing on the "Digital processing of audio and video information" discipline, the student cannot answer on a question about the Nyquist-Shannon sampling theorem. But by reminding him about an essence of this theorem (e.g. what the sampling rate is and what value of the sampling rate is necessary to choose for analog-to-digital conversion), he, possibly, will remember the necessary formula.

It is possible to come to the conclusion that the concept of the test tasks in the order in which it has been studied forces the student to recall material consistently as though he was answering questions from the teacher.

For presentation of test tasks by way of studying DU, it is convenient to use a cognitive map of a subject discipline from a mathematical point of view that represents a focused weighted graph. We shall consider the cognitive map of a certain subject domain (Fig. 1) and, for simplification, we shall accept that the weight of the relations between DU equals 1. In Figure 1, the part of cognitive map of the discipline consisting of $7 \mathrm{DU}(\mathrm{a}, \mathrm{b}, \mathrm{c}$, $\mathrm{d}, \mathrm{e}, \mathrm{f}, \mathrm{g}$ ) is presented.

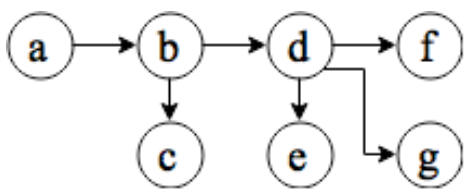

Figure 1. The part of cognitive map with DU a, b, c, d, e, f, g

Two of the most famous algorithms of searching graph data structures are Depth-first search (DFS) and Breadthfirst search (BFS). For the task of DU representation by the way of learning it, it is convenient to use a Depth-first search. 
First, define the consequence relation of didactic units. DU $b$ is next after DU $a(b \Leftarrow a)$, if it is necessary to learn DU $a$ before DU $b$. Thus, the size of the importance of such we shall designate as WEIGHT $(b \Leftarrow a$ ).

For presentation of DU by the order of learning, let us describe the model of subject domain with the help of the following operator system (1).

$$
\left\{\begin{array}{l}
\operatorname{REL}(x, y, w, d):=(\exists x, y \in d)(y \Leftarrow x \& w=\operatorname{WEIGHT}(y \Leftarrow x)), \\
F I N D \_S T(s):=(\operatorname{REL}(s, a, w 1, d) \& \operatorname{not}(\operatorname{REL}(b, s, w 2, d))), \\
F I N D \_D E(s):=\left(R E L(s, f, w, d) \& F I N D \_D E(f)\right), \\
F I N D:=\left(F I N D \_S T(s) \& F I N D \_D E(s)\right),
\end{array}\right.
$$

Where:

$R E L(x, y, w, d)$ - statement describing relationships between DU of the subject domain;

$x$ - is DU, which is necessary to learn to understand the DU $y$;

$w$ - the weight of the relation between DU $x$ and $y$, i.e. the grade of DU $x$ knowledge importance by DU $y$ learning;

$d$ - set of DU related to some discipline;

$F I N D \_S T(s)$ — the operator for finding a starting DU;

$s$ - starting DU with which studying a subject domain begins;

$a, b$ - certain DU that belong to the didactic domain set of discipline $d$ subject domain;

$w 1$ - weight of relation between DU $s$ and $a$;

$w 2$ - weight of relation between DU $b$ and $s$;

$F I N D \_D E(s)$ — the recursive operator for finding of all subsequent DU after starting by way of their studying;

$f$ - following DU after $s$;

FIND - operator for finding a starting and all following DU by way of their being studied.

The described operational model can be realized in the logic programming language SWI-Prolog [14]. The code of cognitive map realization on an example of discipline "Digital processing of audio and video information" subject domain and algorithm of DU list representation by the way of studying is shown in Listing 1.
LISTING I.

COGNITIVE MAP OF D DisCiPLINE "DigITAL PROCESSING OF AUDIO AND VIDEO INFORMATION" AND ALGORITHM OF DU LIST REPRESENTATION BY THE WAY OF STUDYING

rel('Analog signal', 'Digital signal',1,'Digital processing of audio and video information').

rel('Digital signal', 'Analog-to-digital conversion',1,'Digital processing of audio and video information').

rel('Digital signal', 'Digital-to-analog conversion',1,'Digital processing of audio and video information').

rel('Analog-to-digital conversion','Sampling',1,'Digital processing of audio and video information').

rel('Analog-to-digital conversion','Quantization',1,'Digital processing of audio and video information').

rel('Sampling', 'Sampling rate',1,'Digital processing of audio and video information').

rel('Sampling rate', 'Nyquist-Shannon sampling theorem',1,'Digital processing of audio and video information').

rel('Quantization', 'Quantization bit count',1,'Digital processing of audio and video information').

rel('Nyquist-Shannon sampling theorem', 'Aliasing',1,'Digital processing of audio and video information').

find_st(X):- rel(X,_,__), $\operatorname{not}\left(\operatorname{rel}\left(, X, \ldots, \_\right)\right.$, write(X), write('ไn'),!.

find_de(X):- rel(X,Y,_,_, write(Y), write(' $(n ')$, find_de(Y).

find:- find_st $(X)$, find_de $(X)$.

Predicate rel/4 is used to define the cognitive map links of the discipline subject domain (fig. 2). The first term is the DU that is necessary to understand the DU, which is written in the second term. The third term is the weight of the certain relation, and the fourth is the name of discipline.

With the help of predicate find_st/1 (Listing 1) - the conclusion of starting, the first DU of a certain discipline is realized and the predicate find_de/1 finds and represents all DU connected with the stated. Predicate find allows calling predicates find_st $/ 1$ and find_de/1, described above, consecutively, and as a result, the list of the DU is realized in the order of learning in the course.

The Depth-first search usage allows obtaining DU chains by the order of learning; for example the chain "Analog signal $\rightarrow$ Digital signal $\rightarrow$ Analog-to-digital conversion $\rightarrow$ Sampling $\rightarrow$ Sample rate $\rightarrow$ NyquistShannon sampling theorem $\rightarrow$ Aliasing" demonstrates the learning order of DU necessary to understand DU "Aliasing."

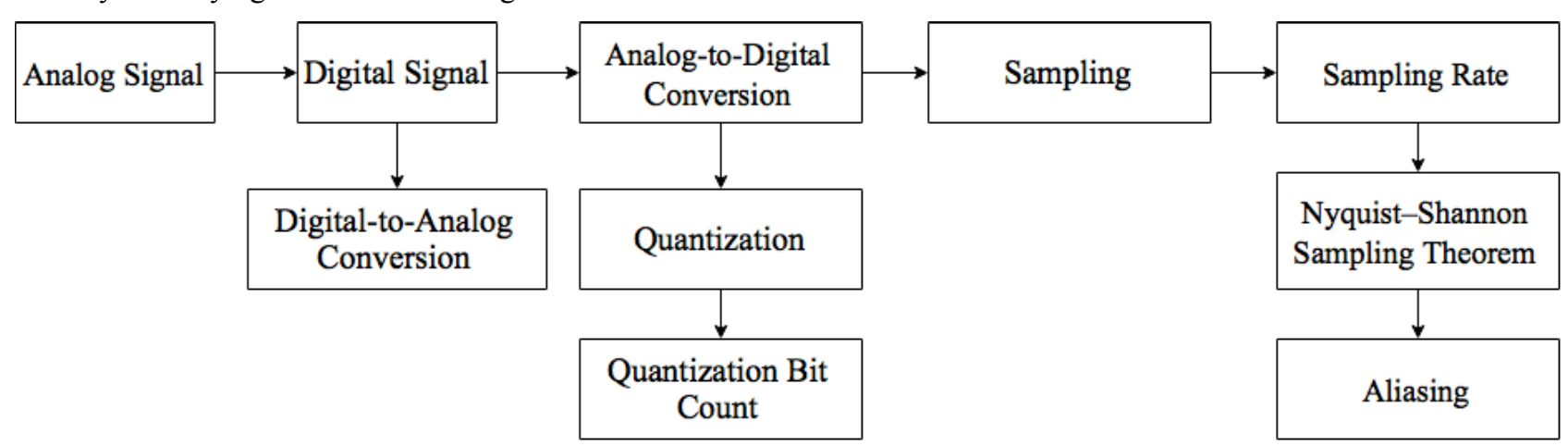

Figure 2. The part of discipline "Digital processing of audio and video information" cognitive map

A Breadth-first search of a certain graph, in turn, divides the DU into levels that do not allow connecting the DU on different levels. In Fig. 3, the DU of the "Digital processing of audio and video information" discipline is presented in a kind of pyramid divided into learning levels. The lower a DU is, the more DU that need to be learned for its understanding. That is why a pyramid shape was chosen for presentation of the levels of study. 


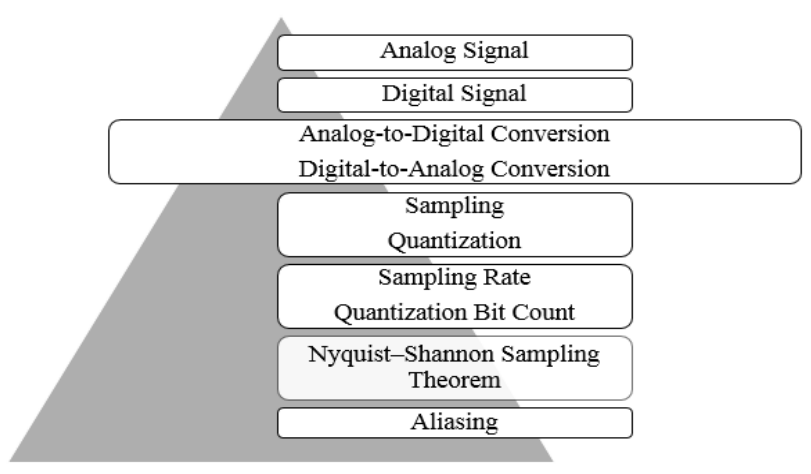

Figure 3. DU of "Digital processing of audio and video information" discipline divided into levels of learning

\section{EXTENSION Of THE Model BASEd ON KNOWLEDGE SPACES}

Knowing the order of learning the DU, the discipline cognitive map can be transformed to a knowledge space, which is represented as a combinative structure of the possible conditions of student knowledge [15].

The theory of knowledge spaces and its practical usage allow describing the knowledge and experience of a tutor in a mechanical way and providing program access to them. Thus, the system can work with a much larger number of questions than the tutor, providing faster and more effective assessment of knowledge this way.

The condition of student knowledge may be presented as a list of didactic units from a certain sphere on the test task, on which he can give an answer in the ideal conditions (without a time limit, emotional stress, etc.). However, sometimes mistakes are believed to be due to negligence. It is necessary to consider that a student, who does not have real knowledge of the asked question, can guess the correct answer. This way the condition of student knowledge is not specifically observable and conclusions about it, based on answers on the test tasks, cannot be done.

In Fig. 4, the knowledge space for the cognitive map from Fig. 1 is presented, i.e. for sphere $Q=\{a, b, c, d, e, f$, $g$ \}, within view of learning the DU sequence. Certain knowledge space presents the structure of knowledge: $K=\{\emptyset,\{a\},\{a, b\},\{a, b, c\},\{a, b, d\},\{a, b, c, d\},\{a, b, d$, $e\},\{a, b, d, f\},\{a, b, d, g\},\{a, b, d, e, f\},\{a, b, d, f, g\}$, $\{a, b, d, e, g\},\{a, b, d, e, f, g\},\{a, b, c, d, e\},\{a, b, c, d, f\}$, $\{a, b, c, d, g\},\{a, b, c, d, e, f\},\{a, b, c, d, f, g\},\{a, b, c, d$, $e, g\}, Q\}$.

This structure contains 20 conditions. The graph edges reflect the attitudes of a covering between sets of DU that are defining one or another condition of knowledge: the edge that is connecting the condition $K$ and condition $K^{\prime}$, which is on the right on the graph, means that $K \subset K^{\prime}$ (where $\subset$ means strict inclusion) and that condition $K^{\prime \prime}$, that is $K \subset K^{\prime \prime} \subset K^{\prime}$, does not exist. Such a graph presentation is used very often [16]. When the graph is viewed from left to right, the process of revision is repeated: the subject knows nothing about the data domain and is in the condition $-\varnothing$. Viewing the graph from left to right, the knowledge progresses from a condition to a condition one step at a time, following one way on the graph, while the knowledge of subject matter in perfection is not reached in condition $Q$ [16].

Based on an assessment of various DU learning levels, the certain condition of the student's knowledge may be correlated with the ideal conditions, shown in the knowledge space and may describe the full development of each DU. Having defined the ideal conditions the current condition of the student is closest to, it is possible to track further ways of learning the studied material and the DU by knowledge space. Examples of further learning paths based on the current state of knowledge are given in Table I.

If the current knowledge condition of the student does not conform to one of the ideal conditions, it can specify that the testing has shown doubtful results on any DU. Mistakes in an assessment could arise if the student has guessed the true answers or has given incorrect answers (knowing thus true), for example because of a technical defect in testing system or incorrect test tasks.

\section{CONCLUSION}

Owing to the cognitive maps of subject matter used in ELC-HE, it is possible to realize not only the mechanism of the intelligent assistant [7], but to correct the algorithm for computer testing in an testing subsystem due to a conclusion of test tasks by way of studying didactic units. The proposed algorithm for representation of didactic units by the way of studying can be used in intelligent tutoring systems, written in SWI-Prolog logic programming language.

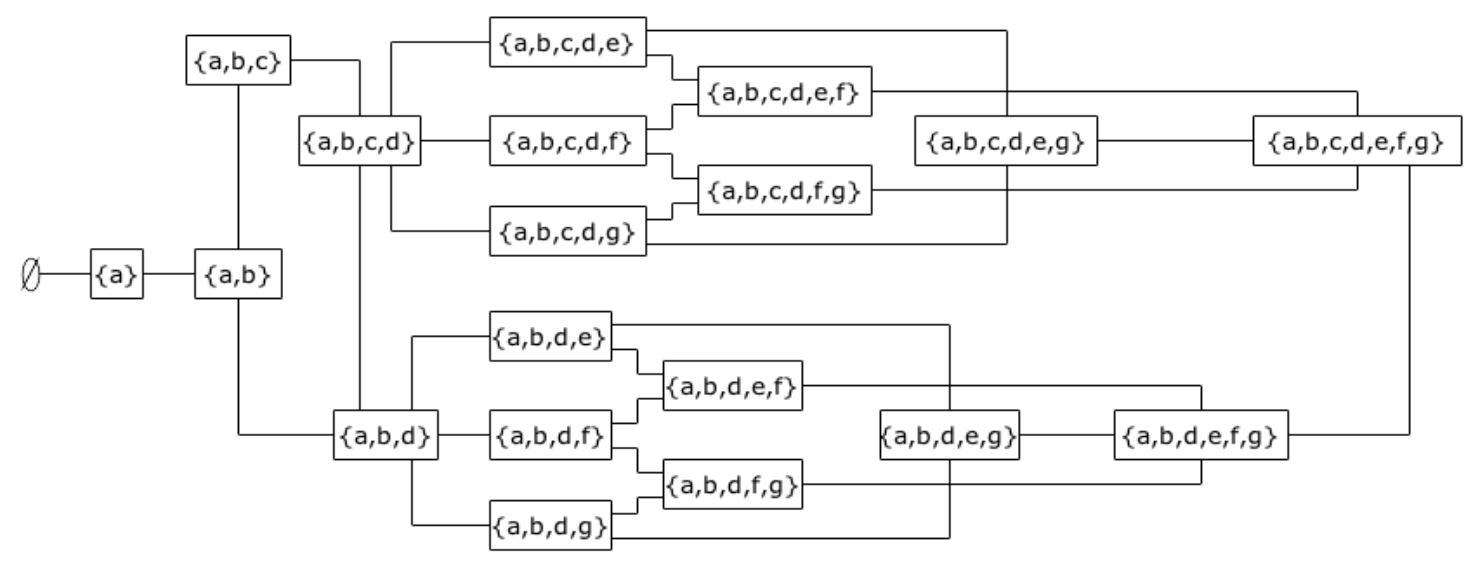

Figure 4. The knowledge space 
TABLE I.

POSSIBLE FURTHER LEARNING PATHS

\begin{tabular}{|c|c|c|}
\hline $\begin{array}{l}\text { Current state of } \\
\text { knowledge }\end{array}$ & $\begin{array}{l}\text { Possible further state of } \\
\text { knowledge }\end{array}$ & $\begin{array}{c}\text { DU student need to } \\
\text { learn to achieve } \\
\text { new state of } \\
\text { knowledge } \\
\end{array}$ \\
\hline$\varnothing$ & $\{a\}$ & $\mathrm{A}$ \\
\hline$\{a\}$ & $\{a, b\}$ & $\mathrm{B}$ \\
\hline \multirow{2}{*}{$a, b$} & $\{a, b, c\}$ & $\mathrm{C}$ \\
\hline & $\{\mathrm{a}, \mathrm{b}, \mathrm{d}\}$ & $\mathrm{D}$ \\
\hline$\{a, b, c\}$ & $\{a, b, c, d\}$ & $\mathrm{D}$ \\
\hline \multirow{4}{*}{$\mathrm{a}, \mathrm{b}, \mathrm{d}$} & $\{a, b, c, d\}$ & $\mathrm{C}$ \\
\hline & $\{a, b, d, e\}$ & $\mathrm{E}$ \\
\hline & $\{\mathrm{a}, \mathrm{b}, \mathrm{d}, \mathrm{f}\}$ & $\mathrm{F}$ \\
\hline & $\{a, b, d, g\}$ & $\mathrm{G}$ \\
\hline \multirow{2}{*}{$\mathrm{a}, \mathrm{b}, \mathrm{d}, \mathrm{e}$} & $\{\mathrm{a}, \mathrm{b}, \mathrm{d}, \mathrm{e}, \mathrm{f}\}$ & $\mathrm{F}$ \\
\hline & $\{a, b, d, e, g\}$ & G \\
\hline \multirow{2}{*}{$\mathrm{a}, \mathrm{b}, \mathrm{d}, \mathrm{f}$} & $\{\mathrm{a}, \mathrm{b}, \mathrm{d}, \mathrm{e}, \mathrm{f}\}$ & $\mathrm{E}$ \\
\hline & $\{a, b, d, f, g\}$ & G \\
\hline \multirow{2}{*}{$\mathrm{a}, \mathrm{b}, \mathrm{d}, \mathrm{g}$} & $\{a, b, d, f, g\}$ & $\mathrm{F}$ \\
\hline & $\{a, b, d, e, g\}$ & $\mathrm{E}$ \\
\hline$\{a, b, d, e, f\}$ & \multirow{3}{*}{$a, b, d, e, f, g$} & $\mathrm{G}$ \\
\hline$\{a, b, d, f, g\}$ & & $\mathrm{E}$ \\
\hline$\{a, b, d, e, g\}$ & & $\mathrm{F}$ \\
\hline \multirow{3}{*}{$\mathrm{a}, \mathrm{b}, \mathrm{c}, \mathrm{d}$} & $\{\mathrm{a}, \mathrm{b}, \mathrm{c}, \mathrm{d}, \mathrm{e}\}$ & $\mathrm{E}$ \\
\hline & $\{\mathrm{a}, \mathrm{b}, \mathrm{c}, \mathrm{d}, \mathrm{f}\}$ & $\mathrm{F}$ \\
\hline & $\{a, b, c, d, g\}$ & G \\
\hline \multirow{2}{*}{$a, b, c, d, e$} & $\{\mathrm{a}, \mathrm{b}, \mathrm{c}, \mathrm{d}, \mathrm{e}, \mathrm{f}\}$ & $\mathrm{F}$ \\
\hline & $\{\mathrm{a}, \mathrm{b}, \mathrm{c}, \mathrm{d}, \mathrm{e}, \mathrm{g}\}$ & G \\
\hline \multirow{2}{*}{$\mathrm{a}, \mathrm{b}, \mathrm{c}, \mathrm{d}, \mathrm{f}$} & $\{\mathrm{a}, \mathrm{b}, \mathrm{c}, \mathrm{d}, \mathrm{e}, \mathrm{f}\}$ & $\mathrm{E}$ \\
\hline & $\{a, b, c, d, f, g\}$ & $\mathrm{G}$ \\
\hline \multirow{2}{*}{$a, b, c, d, g$} & $\{\mathrm{a}, \mathrm{b}, \mathrm{c}, \mathrm{d}, \mathrm{f}, \mathrm{g}\}$ & $\mathrm{F}$ \\
\hline & $\{a, b, c, d, e, g\}$ & $\mathrm{E}$ \\
\hline$\{\mathrm{a}, \mathrm{b}, \mathrm{c}, \mathrm{d}, \mathrm{e}, \mathrm{f}\}$ & \multirow{3}{*}{$\mathrm{a}, \mathrm{b}, \mathrm{c}, \mathrm{d}, \mathrm{e}, \mathrm{f}, \mathrm{g}$} & $\mathrm{G}$ \\
\hline$\{a, b, c, d, f, g\}$ & & $\mathrm{E}$ \\
\hline$\{\mathrm{a}, \mathrm{b}, \mathrm{c}, \mathrm{d}, \mathrm{e}, \mathrm{g}\}$ & & $\mathrm{F}$ \\
\hline$\{\mathrm{a}, \mathrm{b}, \mathrm{d}, \mathrm{e}, \mathrm{f}, \mathrm{g}\}$ & $\{\mathrm{a}, \mathrm{b}, \mathrm{c}, \mathrm{d}, \mathrm{e}, \mathrm{f}, \mathrm{g}\}$ & $\mathrm{C}$ \\
\hline
\end{tabular}

Using knowledge spaces in conjunction with cognitive maps allows determining the current state of knowledge of the student and possible directions for further training, taking into account the sequence of studying the didactic units and possible arbitrary order of studying the didactic units at the same level.

The proposed methodology can be used by researchers, teachers and engineers for support of the educational process and control of student knowledge that improve the quality of electronic education.

\section{REFERENCES}

[1] D.I. Popov, E.D. Popova, Examination of Test Tasks Quality: the Manual. Moscow: MSUPA, 2008.

[2] O.Y. Lazareva, "Historical Background and Development of ELearning Systems", The MSUPA Bulletin, no 9, 2013, pp. 76-86.
[3] D.I. Popov, K.I. Yakubovsky, D.G. Demidov, "Fuzzy Model of Test Tasks Selection for Personnel Certification in Printing Companies", The Higher Educational Institutions News. Problems of Polygraphy and Publishing, no 3, 2014, pp. 3-9.

[4] D.I. Popov, T.I. Komolova, E.D. Popova, K.I. Yakubovsky, "Features of Formalization of Competence Approach in Training in the Field of Polygraphy and Publishing", The Higher Educational Institutions News. Problems of Polygraphy and Publishing, no 3, 2013, pp. 106-112.

[5] A.V. Ostroukh, D.I. Popov, D.G. Demidov, N.E. Surkova, "Development of the Rules Base for an Expert System Choice Adaptive Learning Strategy", ARPN Journal of Engineering and Applied Sciences, vol. 10, issue 10, 2015, pp. 4430-4435.

[6] D.I. Popov, D.G. Demidov, "An Adaptive Strategy for Education Personnel Certification", In the World of Scientific Discoveries, no 9, 2011, pp. 65-71.

[7] O.Y. Lazareva, "Architecture of Intelligent Tutoring System for Evaluation of Students' Competencies", The Higher Educational Institutions News. Problems of Polygraphy and Publishing, no 5, 2014, pp. 55-64.

[8] D.I. Popov, O.Y. Lazareva, "The Fuzzy Overlay Student Model in an Intelligent Tutoring System", The Scientific Bulletin of the Moscow State Technical University of Civil Aircraft, no 213 (3), 2015, pp. 141-148.

[9] N. Sukajaya, K.E. Purnama, M.H. Purnomo, "Intelligent Classification of Learner's Cognitive Domain using Bayes Net, Naïve Bayes, and J48 Utilizing Bloom's Taxonomy-based Serious Game", International Journal of Emerging Technologies in Learning, vol. 10, no 2, 2015, pp. 46-52. http://dx.doi.org/10.3991/ ijet.v10i2.4451

[10] N. Capuano, G.R. Mangione, A. Pierri, S. Salerno, "Personalization and Contextualization of Learning Experiences based on Semantics", International Journal of Emerging Technologies in Learning, vol. 9, no 7, 2014, pp. 5-14. http://dx.doi.org/10.3991/ijet.v9i7.3666

[11] V.A. Nguyen, "Toward an Adaptive Learning System Framework: Using Bayesian Network to Manage Learner Model", International Journal of Emerging Technologies in Learning, vol. 7, no 4, 2012, pp. 38-47. http://dx.doi.org/10.3991/ ijet.v7i4.2290

[12] O.Y. Lazareva, "Cognitive Map of the Domain Model in the Intelligent Tutoring System", Proc. of the VIII International scientifically-practical conference "Scientific and Educational Information Environment of XXI Century", Petrozavodsk, 2014, pp. 134-137.

[13] I.Y. Ustinov, Definitions of the Basic Terms of Didactics of the High Military School: the manual. Voronezh: MAEU, 2010.

[14] O.Y. Lazareva, "The Usage of SWI-Prolog in a Web-based Intelligent Tutoring System", Proc. of the International Scientifically-Practical Conference "Actual Problems of a Modern Science", Ufa, 2014, pp. 11-16.

[15] J.-C. Falmagne, J.-P. Doignon, Learning Spaces Interdisciplinary Applied Mathematics. Berlin: Springer Science \& Business Media, 2011.

[16] D.I. Popov, Automation of Management of Processes of Certification of the Personnel of the Enterprises of the Industry: the Monography. Moscow: MSUPA, 2007.

\section{AUTHORS}

D.I. Popov is with the Department of Computer and Information Technology, Moscow State University of Printing Arts, Pryanishnikova 2A, Moscow 127550 Russia (e-mail: damitry@mail.ru).

O.Y. Lazareva is with the Department of Computer and Information Technology, Moscow State University of Printing Arts, Pryanishnikova 2A, Moscow 127550 Russia (e-mail: lazarevaoy@gmail.com).

Manuscript received 16 July 2015. Published as resubmitted by the authors 15 November 2015 .. 